\title{
La evolución de las migraciones interiores en España: una evaluación de las fuentes demográficas disponibles
}

\author{
Joaquín Susino Arbucias \\ Universidad de Granada. Departamento de Sociología \\ jsusino@ugr.es
}

Recibido: 13-01-2011

Aceptado: 09-05-2011

\section{Resumen}

En este trabajo se revisan las fuentes demográficas para el estudio de las migraciones interiores existentes en España. Se comentan sus diferencias y se compara la evolución de las migraciones que se deduce de cada una de las fuentes. Primero, la evolución anual; en segundo lugar, por decenios desde 1960, y, en último lugar, para el periodo más reciente. Esto nos permite analizar la consistencia entre algunas de las fuentes, pero también sus incongruencias. Las que ofrecen resultados más consistentes son las fuentes censales y la Encuesta Sociodemográfica. Las que menos, la Encuesta de Migraciones y las estadísticas de variaciones residenciales. Los problemas que plantean ambas tienen un origen común en la gestión del padrón de habitantes que condiciona, en el primer caso, la extracción de la muestra y, en el segundo, el registro administrativo de las altas y las bajas padronales. Para mejorar sus resultados, es necesario abordar una tarea pendiente en la gestión del padrón: asegurar que la situación de empadronamiento responda a la realidad residencial de los ciudadanos. Se aboga por dedicar más atención a la discusión sobre la idoneidad de cada una de las fuentes dependiendo del objeto y de los objetivos de la investigación a realizar, pero se echa en falta en muchos estudios una mayor reflexión sobre el tema.

Palabras clave: migración interior; fuentes demográficas; censo de población; padrón municipal; encuestas demográficas; migraciones; migrantes.

\section{Abstract. The evolution of internal migration in Spain: An assessment of available demographic sources}

This article reviews the demographic sources available in Spain for the study of internal migration. We outline the differences between each of these sources and compare how each source tracks internal migration in terms of annual evolution, measured by decade since 1960, and in recent times. These comparisons allow us to check both the constancy and incongruities between the different sources. We find that the most consistent results are obtained from the Census Data and the Encuesta Sociodemográfica (Sociodemographic Survey). The Encuesta de Migraciones (Migrations Survey) and the Estadisticas de Variaciones 
Residenciales (Residential Change Statistics) are less reliable. The problems with the last two sources are associated with the management of the Padrón de Habitantes (local population register), which alters the sampling for the Encuesta de Migraciones and the accurate registration of additions and withdrawals for the Estadisticas de Variaciones Residenciales. To improve the results of these sources, it is necessary to impute a crucial task on the management of the Padrón: to ensure that the register accurately corresponds to the real residential situation of the population. We argue that studies must pay closer attention to the suitability of each source in relation to their object of research and its objectives. But in many studies such deeper reflection is lacking.

Key words: internal migration; demographic sources; census; population register, demographic surveys; migrations; migrants.

\section{Sumario}

Introducción

1. Fuentes demográficas sobre migraciones interiores en España

2. La evolución anual de las migraciones según las distintas fuentes

3. La evolución de las migraciones por décadas, desde 1961 hasta la actualidad
4. ¿Se debe todo el incremento de la movilidad que reflejan las EVR a la mayor presencia de extranjeros?

5. Conclusiones

6. Referencias bibliográficas

\section{Introducción}

A pesar de la importancia que tuvieron en el pasado en la investigación social, las migraciones interiores han pasado a un segundo plano, frente al empuje de los estudios sobre la inmigración internacional. No obstante, no es poca la literatura que, sobre migraciones interiores, se ha producido en las últimas décadas y que aún hoy se sigue produciendo. Además, una nueva preocupación, relativa a la movilidad interior de los inmigrantes extranjeros, reaviva el interés por esta cuestión (Recaño, 2002; Pumares et al., 2006; Recaño y Domingo, 2006). Con independencia de estas razones, las migraciones interiores son fundamentales en la evolución de los sistemas urbanos, de los mercados de trabajo o de la estructura social. Esto es motivo suficiente para hacerlas objeto de la investigación social.

En España, hay una considerable bibliografía sobre las migraciones interiores desde distintas perspectivas de las ciencias sociales: sociología, geografía, economía e historia, especialmente (Laraña, 1993; Silvestre, 2002). Estos trabajos suelen analizarlas partiendo de alguna de las fuentes estadísticas disponibles, analizando su volumen y su evolución, a veces complementando el análisis con datos provenientes de una fuente alternativa. Sin embargo, pocos entran a analizar las profundas divergencias existentes entre unas y otras fuentes. El problema de estas fuentes es que ofrecen volúmenes de migraciones y migrantes distintos, dibujan evoluciones anuales y por periodos divergentes, $\mathrm{y}$ 
composiciones, en cuanto a los tipos de migraciones preponderantes, que tampoco coinciden. En la literatura sobre migraciones, hay referencias frecuentes a estos problemas y a las deficiencias de algunas fuentes, pero no un tratamiento sistemático. Esto es lo que se intenta a continuación, aunque limitado a la cuantificación de su evolución.

Este artículo no pretende poner en cuestión las fuentes existentes. En todo caso, se espera aclarar qué problemas se presentan cuando queremos analizar la evolución de las migraciones interiores en los últimos cincuenta años en España. Que una fuente no sea válida a estos efectos, no significa que no pueda serlo para otro tipo de análisis, como, por ejemplo, el estudio de la estructura territorial de los flujos migratorios. De entrada, a pesar de las discrepancias entre fuentes, no parece que ninguna de ellas sea prescindible, aunque algunas puedan y deban mejorar.

Por otra parte, conviene aclarar, antes de proseguir, que cuantificar las migraciones supone entrar en un debate conceptual sobre su definición (Courgeau, 1988; Domenach y Picouet, 1987; Faura y Gómez, 2002). Sin embargo, no es este el objeto del presente artículo, que no intenta cuantificar las migraciones, sino evaluar las fuentes estadísticas disponibles para ello. Por eso, la definición que seguimos es la convencional, que considera la migración como cambio de lugar de residencia, entendiendo éste como la unidad territorial administrativa más pequeña, que en España es el municipio. Esta es una definición ampliamente aceptada, por razones más pragmáticas que conceptuales, puesto que facilita mucho su medición. Por esta razón, cabe calificarla de definición estadística, y es a la que nos atenemos en este artículo.

\section{Fuentes demográficas sobre migraciones interiores en España}

La disponibilidad y la calidad de las fuentes para el estudio demográfico de las migraciones son muy inferiores a las de las fuentes en que se basa el estudio de otros fenómenos demográficos. En España, sólo a partir de la década de 1960, se empieza a generar información estadística sobre migraciones, ya sea a través de las altas y las bajas padronales o de preguntas específicas incluidas en los censos a partir del de 1970. Estas estadísticas se han mantenido y han mejorado, y más recientemente se añade otra fuente, la Encuesta de Migraciones. Por tanto, además de otras encuestas puntuales que recogen información sobre migraciones, en España hay tres fuentes estadísticas que proveen regularmente de datos sobre migraciones interiores.

La fuente más típicamente demográfica, y la primera que aparece en el sistema estadístico español, son los censos. Pero estos no siempre han incluido preguntas específicas sobre migraciones. Además, deberían ser consideradas distintas fuentes en función de la pregunta censal utilizada para recopilar los datos. Actualmente, incluyen tres tipos de preguntas:

- La única pregunta que está presente en los censos más antiguos no es específicamente sobre migraciones, se refiere al lugar de nacimiento. Su uso para 
el estudio de las migraciones se deriva de la comparación entre el lugar de residencia y el lugar de nacimiento. No deja de ser, sin embargo, una fuente relevante, porque es la única existente para determinados periodos (Silvestre, 2001; Tirado et al., 2006) y constituye un buen recurso para el análisis de la migración de retorno (Recaño, 2010; y también, aunque a partir de las EVR, Recaño, 2006; Egea et al., 2005).

- La primera pregunta específica sobre migraciones, incluida por primera vez en el censo de 1970, es la referida al lugar de residencia en una fecha fija anterior. Desde entonces, ha estado presente en todos los censos (ver cuadro 1), siempre referida a la fecha de realización del censo anterior, aunque el de 1991 incorpora una batería de tres preguntas referidas al lugar de residencia en el censo anterior, en la fecha de la renovación anterior del padrón y un año antes. Este tipo de cuestiones se limita a la población que había nacido en la fecha de referencia, por ejemplo la de diez años y más en el caso de interrogar por la residencia en el censo anterior. No es la fuente más utilizada (García Coll y Stillwell, 2000; Feria et al., 2008).

- La segunda pregunta que se ha utilizado es la referida al lugar de residencia anterior al actual, es decir, a la última migración, ya sea sin límite temporal o en el período que va de un censo a otro. A veces, esta pregunta aparece referida solo al año desde el que se reside en el municipio actual, sin inquirir por el lugar de residencia anterior. En unos casos, aparece asociada a la que se hace sobre la residencia en una fecha fija anterior, como es el caso de los censos de 1970 y 1981 y, por tanto, no dan una cifra de migrantes diferente de aquella. En otros, es una pregunta diferente, como en los censos de 1991 y 2001. También se incluyó en las renovaciones de los padrones de 1975 y 1986, que, estadísticamente, pueden considerarse equivalentes a los censos por tratarse de recuentos universales de población que emplean la misma técnica de recogida de datos, aunque tengan una calidad desigual (cuadro 1). Tampoco es la más utilizada en las investigaciones recientes (Cruz et al., 1996).

Los dos últimos censos, los de 1991 y 2001, incluían, además, opciones para investigar la movilidad residencial no migratoria, es decir, los cambios de vivienda dentro del mismo municipio. Argumentar sobre la importancia de esta cuestión para enmarcar el análisis de las migraciones excede los objetivos de este artículo. Nos limitamos a señalar su presencia y las dos formas en que se ha resuelto. La utilizada en 1991, incluyendo una opción, dentro de la pregunta sobre el lugar de residencia en la fecha del censo anterior, sobre la residencia en otro domicilio dentro del mismo municipio. El censo de 2001 optó por una pregunta distinta dentro del cuestionario de vivienda, no del hogar, sobre la fecha de establecimiento del hogar en la vivienda. Combinada con el lugar de residencia anterior, permite una aproximación a los cambios intramunicipales. Es obvio que la formulación del censo de 1991 es mucho más precisa.

Otra fuente específica viene constituida por las estadísticas de variaciones residenciales (EVR), que provienen de la explotación de las altas y bajas en un registro administrativo como es el padrón de habitantes $\mathrm{y}$, por tanto, sujeto 
Cuadro 1. Las preguntas sobre migraciones en los censos y renovaciones del padrón

Censo de 1970

Pregunta 7. Residencia anterior. Si vino a residir a este municipio después de 1960 ¿en qué mes y año vino? ¿en qué municipio y provincia (o país) residía en 31 de diciembre de 1960 ?

Padrón de 1975

Pregunta 12. Residencia. ¿Ha residido siempre en este municipio? Ponga X donde corresponda y año de llegada si procede?

\section{Censo de 1981}

Pregunta 7. Lugar de residencia en 31-12-1970. Sólo para las personas mayores de 10 años, que vinieron a residir a este municipio después de 1970. Indique: El municipio en que residía en 31 de diciembre de 1970. La provincia (o país, si vino del extranjero) en que residía en 31 de diciembre de 1970. El año en que vino.

\section{Padrón de 1986}

Pregunta 11. Para los que no han residido siempre en el municipio. Indique el año de llegada (año en que fijó su residencia actual en este municipio) y la provincia y municipio o país de residencia anterior.

\section{Censo de 1991}

Cuestionario general

Pregunta 14. Lugar de residencia habitual hace un año (1 de marzo de 1990): No había nacido. Residía en este municipio, en el mismo domicilio. Residía en este municipio, en otro domicilio. Residía en otro municipio de España: municipio, provincia. Residía en el extranjero: país.

Pregunta 15. Lugar de residencia habitual hace cinco años (1 de marzo de 1986): mismas opciones que la pregunta 14 .

Pregunta 16. Lugar de residencia habitual hace diez años (1 de marzo de 1981): mismas opciones que la pregunta 14.

Pregunta 17. Sólo para las personas que en los últimos 10 años han residido en otro municipio. Indique el año en que fijó por última vez su residencia en este municipio y el lugar de procedencia. Año. Procedía de otro municipio de España: municipio, provincia. Procedía del extranjero: país.

\section{Censo de 2001}

Cuestionario de hogar

Pregunta 5. ¿Desde qué año reside (aunque sea desde que nació) en: España, esta comunidad autónoma, este municipio. Si antes residía en otro municipio o país, escríbalo.

Pregunta 6. ¿En qué municipio (o país) residía el 1 de marzo de 1991? En este municipio (o no había nacido aún). En otro municipio o país; provincia.

Cuestionario de vivienda

Pregunta 1. ¿Desde qué año residen en esta vivienda? Si no llegaron todos a la vez, refiérase al primero que lo hizo.

Fuente: elaboración propia. Las cifras corresponden al número de identificación de las preguntas en el cuestionario. 
a las posibilidades y limitaciones derivadas de ese carácter de registro administrativo. Existen desde principios de los años sesenta, aunque entonces aun no recibían ese nombre, pero, a lo largo de este tiempo, han experimentado cambios muy profundos ligados a la gestión del padrón. Son la fuente más utilizada actualmente, pero las EVR no siempre son citadas de la misma forma. Determinados trabajos señalan los anuarios estadísticos del INE, sin tener en cuenta que estos son la fuente bibliográfica, pero no la fuente estadística, que son las EVR (Santillana del Barrio, 1982; Ávila, 1993). La aparición de los institutos estadísticos autonómicos ha complicado algo la situación (García Coll y Sánchez Aguilera, 2001), puesto que algunos autores citan los datos por la publicación en la que aparecen, con lo cual obvian el origen estadístico de los mismos, es decir, la operación estadística en que se basan los datos (Galdós y Ruiz Urrestarazu, 2001; Torres Elizburu, 2007).

La última fuente es la Encuesta de Migraciones (EM), la más reciente, que existe desde 1980. Se realiza junto con la Encuesta de Población Activa. Desde entonces, ha experimentado varios cambios, algunos de gran calado metodológico, pasando por diversas etapas (INE, 2002; Martí y Ródenas, 2004; INE, 2008). Como su nombre indica, se trata de una encuesta, aunque basada en una muestra muy amplia, mientras que las estadísticas de variaciones residenciales explotan la totalidad de los registros y los censos son universales. La pregunta de la encuesta se refiere al lugar de residencia un año antes, no sobre todos los movimientos realizados durante el periodo. Ofrece información de los migrantes con relación al mercado laboral, lo que le otorga singularidad frente a otras fuentes. No obstante, es poco utilizada y muy criticada, hasta el punto de que se ha sugerido la interrupción de su elaboración y publicación (Ródenas y Martí, 2005).

Este acercamiento podría hacernos pensar que pecamos de exceso de fuentes. No obstante, una ojeada a las estadísticas de otros países muestra las variedad de opciones posibles y que una de las grandes dificultades para hacer comparaciones internacionales de las migraciones internas reside precisamente en esa diversidad (Bell, 2005). Problema que frecuentemente se reproduce dentro de cada país.

Existe un tipo de fuentes muy importantes, pero que no son periódicas, sino puntuales en el tiempo. Son algunas encuestas de ámbito nacional y tamaño muestral suficientemente grande. La más importante es la Encuesta Sociodemográfica de 1991 (ESD), que es muy útil para comparar con las demás fuentes e intentar evaluarlas conjuntamente. Es una encuesta retrospectiva, que investiga todos los acontecimientos demográficos de toda la vida de los encuestados. Permite investigaciones que pongan en relación distintos eventos y situaciones en la vida de los entrevistados (Recaño y Roig, 2003). Se refiere tanto a migraciones, como a cambios de vivienda, aunque en este caso limitados a un periodo más corto (Zamora y Serrano, 2000). Algunos autores han utilizado otras encuestas para estudiar las migraciones aunque no hubiesen sido específicamente diseñadas para ello, como la Encuesta de Equipamiento y Nivel Cultural de las Familias (Ballester Ros, 1978). 
Por supuesto, las migraciones pueden ser estudiadas indirectamente mediante el cálculo de saldos migratorios, pero no por ello constituyen una fuente diferenciada. Hay muchos estudios basados en el cálculo de saldos migratorios, con distintos niveles de desagregación espacial. Entre estos, debemos resaltar los clásicos de (García) Barbancho (1967, 1975).

Por último, se pueden utilizar otras fuentes para analizar las migraciones, aunque no incluyan preguntas específicas sobre ellas. Es el caso del uso de los padrones de habitantes, mediante su explotación nominal, para analizar las redes migratorias al principio del siglo xx (García Abad, 2002).

Las cifras derivadas de unas y otras fuentes no pueden coincidir, puesto que algunas indagan sobre las migraciones, es decir, sobre todos los cambios de lugar de residencia realizados por los individuos investigados; mientras que otras lo hacen sobre migrantes, es decir sobre los efectivos demográficos que, en un determinado momento, están presentes y declaran haber migrado. Incluso cuando se investiga sobre migrantes, no es lo mismo preguntar por la residencia diez años antes, que por un año antes, que por la última migración. Temas sobre los que volveremos más adelante.

La migración pone en relación un lugar de origen y otro de destino del movimiento, lo que invita a estudiar no solo los volúmenes de migraciones y migrantes, o sus características sociodemográficas, sino también los flujos de origen y destino. Desde los años sesenta, censos y EVR permiten estudiar los flujos interprovinciales, sobre lo que ya hay en España una larga tradición de análisis. Pero, aunque se censa al universo de individuos residentes en el país, hasta hace poco las tabulaciones publicadas se extraían de una muestra de los cuestionarios. Más recientemente, la explotación se ha hecho a partir de la totalidad de los registros censales (en los censos de 1991 y 2001), ofreciendo datos para muchas variables y muy desagregados territorialmente (a nivel municipal, de entidad de población o de sección censal). Solo entonces, a través de peticiones de explotación específicas y con las debidas garantías para preservar el secreto estadístico, es posible analizar los flujos entre municipios, tanto con los últimos censos, como con las EVR. Pero son escasos los estudios que se basen en el análisis de matrices de flujos entre municipios, ya sea a partir de los censos (Cruz et al., 1996; Feria et al., 2008), ya sea a partir de las EVR (Módenes y Recaño, 2003; López Gay, 2007; Pujadas, 2009), limitando el área de estudio a una región, agrupando orígenes y destinos por comarcas o definiendo ámbitos en función de la distancia. La Encuesta de Migraciones, aunque basada en una muestra muy amplia, no permite desagregar los datos territorialmente, puesto que se publican únicamente flujos interregionales que agrupan a comunidades autónomas. Por otra parte, la también reciente disponibilidad de microdatos facilita el análisis de las características sociales (solo en los censos) y demográficas de los migrantes (también en las EVR).

No son abundantes los estudios que dedican una discusión extensa y profunda sobre las fuentes demográficas, aunque dos autoras han dedicado varios trabajos al análisis específico de las estadísticas sobre migraciones (Martí y Ródenas, 2004; Ródenas y Martí, 1997, 2006, 2009a, 2009b). No obstante, 
otros autores tratan, con mayor o menor profundidad, las diferencias entre las fuentes existentes (entre otros, Recaño, 2006). Sin embargo, hay trabajos que utilizan dos tipos de fuentes distintas y no se detienen a evaluar o comentar el origen de las diferencias o a intentar dar cuenta de ellas (Santillana del Barrio, 1982; Bielza, 1987). Algunos trabajos que se plantean como objetivo saber qué ha pasado y por qué, no evalúan a fondo la solvencia de las fuentes utilizadas (Bentolila, 2001, que se apoya en los datos de Bover y Velilla, 1997). Otros que ponen en pie técnicas de análisis más sofisticadas, no parecen considerar necesario tratar de la idoneidad de las fuentes (Maza y Villaverde, 2004). Lo que llama la atención, en este panorama de diversidad de fuentes a veces contradictorias, es precisamente que predominan los estudios que optan por alguna de ellas sin considerar los aspectos metodológicos que subyacen a tal decisión. En la mayoría de los casos, parece que se trata más de una opción impulsada por la disponibilidad que por la idoneidad de la fuente.

\section{La evolución anual de las migraciones según las distintas fuentes}

Aunque todas las fuentes proveen de algún tipo de datos sobre el año de la migración, la principal fuente al respecto son las EVR, por lo que debemos comenzar el análisis de la evolución anual a partir de ellas.

En la figura 1, se recogen las migraciones desde 1960 hasta la actualidad derivadas de las estadísticas de variaciones residenciales. Como se ha dicho, tienen su origen en la explotación estadística de un registro administrativo. Lo que miden no son las migraciones mismas, sino un hecho administrativo como es la comunicación por el interesado de un cambio de domicilio que supone una modificación en el municipio de residencia: un hecho ligado a la migración, pero que no es la migración. No todas las migraciones se incorporarán al registro, mientras que puede haber registros que no se corresponden con hechos realmente ocurridos.

Hasta 1996, el padrón se renovaba cada cinco años, con lo que se volvía a empezar de cero. Esto quiere decir que las migraciones que no hubiesen sido recogidas porque los ciudadanos no se hubiesen dado de alta, ya no serían contabilizadas como tales, porque, al renovarse el padrón, serían inscritos en el nuevo lugar de residencia sin necesidad de que tal hecho apareciese como alta, es decir, como inmigración. Por esta razón, entre 1961 y 1996, cada cinco años se registra un fuerte descenso en la cifra de migraciones. Para muchos autores, la principal deficiencia de esta fuente es su subregistro en dichos años (Pujadas y García Coll, 1995; García Coll y Sánchez Aguilera, 2001). El paso, en 1996, a su gestión como padrón continuo supone un aumento del volumen de migraciones recogidas porque cualquier alta tiene que inscribirse como tal, puesto que deja de haber barridos cada cinco años que ponen al día la situación de residencia sin necesidad de darse de alta.

Por sí mismas, estas pautas ya hacen imposible el análisis de la evolución anual, pero calculando medias móviles de cinco años, se elimina este efecto. Se advierte, entonces, un descenso de las migraciones en la segunda mitad de los 
Figura 1. Evolución anual de las migraciones según las estadísticas de variaciones residenciales

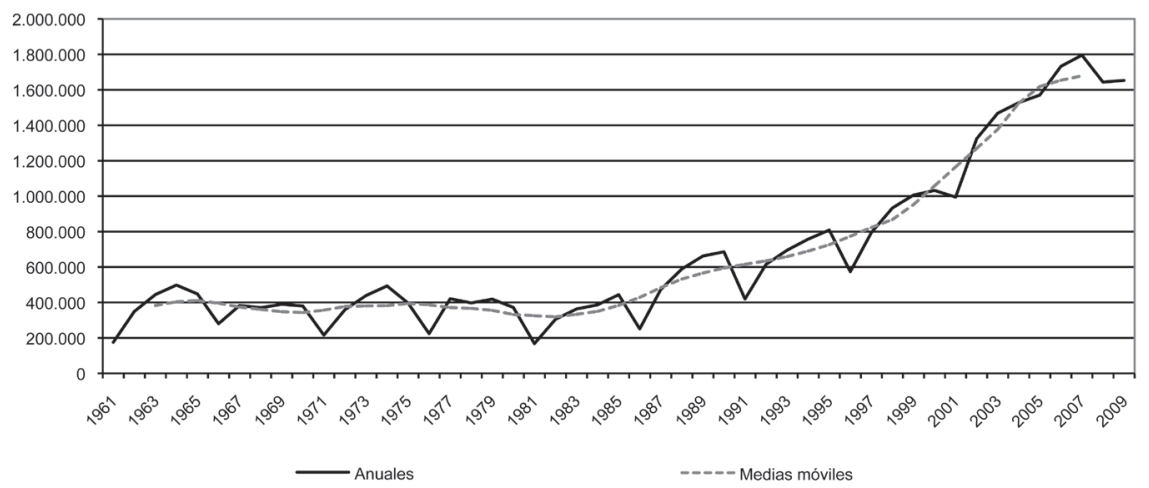

Fuente: elaboración propia a partir de las EVR, en INE, 1991a, 1991b, 1992, 1993a, y anuarios estadísticos (varios años).

sesenta en relación con los años álgidos de la primera mitad, un nuevo aumento en la primera mitad de los setenta, un nuevo descenso, aunque menor en la segunda mitad de los setenta que continúa hasta entrados los ochenta, para, a partir de entonces, empezar a aumentar hasta los últimos años para los que se poseen datos, en que se registra el máximo de migraciones, que cuadriplican el máximo de los sesenta. Curiosamente, en 2001, se registra un descenso respecto al año anterior. Es el año en que se realiza el censo y, aunque este no está ligado al padrón, el envío de una hoja preimpresa para la contrastación de los datos de que ya disponía el padrón parece haber tenido un efecto parecido al de las antiguas revisiones. Desde entonces, se han producido nuevos cambios en la gestión del padrón que se tratan más adelante.

En la figura 2, se recoge el número de migrantes anuales derivado de las demás fuentes: censos, renovaciones del padrón y de la Encuesta de Migraciones. Existe una clara discrepancia entre las cifras de migrantes y de migraciones provenientes de las distintas fuentes. Además, la evolución dibujada por cada una de estas presenta características distintas.

En general, se observa que, en los años inmediatamente anteriores al de realización de censos o padrones, se da una fuerte subida de los migrantes registrados ${ }^{1}$. Cuanto más cerca se está del momento de observación, mayor tiende a ser la cifra de migrantes. Este tipo de preguntas sobre la última migración inevitablemente «deforma» el tiempo. Recordemos que, a pesar de llamarla

1. Los últimos censos, al no coincidir su fecha de referencia con el cambio de año, registran un bajo número de migrantes en ese año, aunque en realidad representa un crecimiento enorme si se toma la media mensual. Por eso, con excepción del censo de 2001, realizado a 1 de noviembre, no se incluyen en el gráfico los migrantes del año en que se hace el censo (ni el padrón de 1986). 
Figura 2. Evolución anual de migraciones y migrantes según distintas fuentes

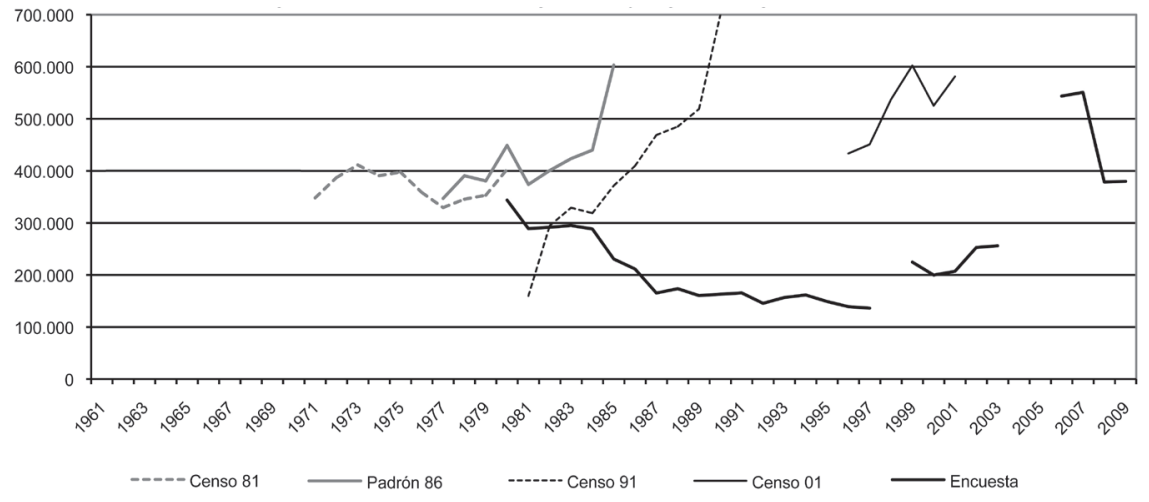

Fuente: elaboración propia a partir de censos y padrones en INE, 1974, 1977, 1985, 1987, 1993c, 2004 y Encuesta de Migraciones (varios años).

«última migración», la pregunta mide migrantes (en su último movimiento), no recogiendo todas las migraciones realizadas durante un periodo determinado. Por tanto, los más antiguos están infrarrepresentados, puesto que el hecho de que una misma persona realice otro más reciente, impide que aparezcan los anteriores. Además, la pregunta incluye a más población según se acerca el momento actual, puesto que las migraciones pueden afectar a los nacidos en fechas más cercanas, a edades en que las migraciones son frecuentes, de carácter familiar. Inevitablemente, los movimientos más recientes predominan sobre los anteriores y es en este sentido en que afirmamos que la pregunta deforma el tiempo. Todo ello con independencia de los problemas asociados a la memoria en la investigación mediante cuestionario.

La pregunta sobre el lugar de residencia en una fecha fija anterior no tiene los mismos efectos sobre el tiempo. Pero cuando se asocia al año de llegada al municipio, se producen las mismas consecuencias. Por eso, las preguntas censales ofrecen casi siempre la misma imagen gráfica: un incremento de las migraciones según se acerca el año censal. Este incremento no responde a la realidad, sino que es producido por el instrumento de medida. Si en algún caso la imagen no es esta, es que debe haberse producido realmente un descenso de las migraciones según se acerca la fecha del censo. Es lo que ocurre con el censo de 1981, que registra mayor número de migrantes en la primera mitad de los setenta que en la segunda; por tanto, realmente debieron caer mucho las migraciones en ese periodo. El padrón de 1986 parece refrendar esa interpretación, con un nuevo incremento posterior, ya entrados los ochenta. El censo de 1991 registra un aumento prácticamente continuo del número de migrantes a lo largo de los años ochenta, igualmente con un brusco aumento el año anterior a la realización del censo. El censo de 2001 ofrece una imagen distinta, sorprendentemente con menos migraciones en 1999 que en años anteriores. 
Parte de esas discrepancias se deben a que todas las fuentes no miden lo mismo: unas migraciones, otras migrantes. Migraciones sólo miden las EVR. Padrones y censos que indagan sobre migrantes no siempre realizan o explotan el mismo tipo de pregunta: unas veces clasifican al migrante cuando fija su residencia en el municipio actual en relación con la residencia a una fecha fija anterior, otras preguntan por la fecha de la última migración. La Encuesta de Migraciones también mide migrantes en relación con la situación de residencia un año antes. Obviamente, las preguntas no son equivalentes, unas sólo se dirigen a las personas que superan cierta edad, diez años si se pregunta por la fecha de residencia diez años antes, otras se refieren a toda la población.

La evolución más sorprendente es la que dibuja la Encuesta de Migraciones, contradictoria con todas las demás fuentes. Desde 1980, un continuo descenso de los migrantes (al menos hasta 1987), en abierta contradicción con EVR. Aunque en este momento nos centramos en las tendencias evolutivas y dejamos para más adelante la comparación de los volúmenes migratorios de las distintas fuentes, es inevitable constatar que el número de migrantes que se deriva de la EM es muy inferior que en las demás fuentes.

La EM comparte con la Encuesta de Población Activa, a la que va asociada como cuestionario específico, parte de sus características metodológicas. Sin embargo, la administración del cuestionario ha experimentado diversos cambios, en parte orientados a resolver la evidente subestimación de las migraciones de esta encuesta, sin conseguirlo. Además de las modificaciones de la propia EPA, sobre todo las relativas a reponderaciones y estimaciones a partir de la muestra, la EM ha atravesado cuatro fases distintas. Durante el período 1980-1986, recogía información durante los cuatro trimestres del año, a partir de las viviendas que entraban a formar parte por primera vez en la muestra de la EPA en cada uno de los trimestres, estimándose el número medio de migrantes en el año. Durante el período 1987-1991, se recogía información solo en el segundo trimestre de cada año. Entre 1992 y 1998, se produjeron varias modificaciones en el cuestionario y ampliaciones de la muestra de la EPA. En 1999, junto a una nueva renovación de la EPA, se vuelve a estudiar a los migrantes en los cuatro trimestres del año, pero siguiendo un procedimiento que permite dos estimaciones diferentes: la primera parecida al periodo 1980-1986, la segunda como media anual de las muestras trimestrales completas, de forma que un método permitía corregir parcialmente la subestimación del otro. Con los cambios metodológicos realizados en la EPA a partir de 2005, la EM se obtiene a partir de una submuestra compuesta por los hogares a los que se realiza la encuesta en la sexta y última entrevista.

Se observa, en la figura 2, que, en esta última fase, la EM estima un mayor volumen de migraciones, pero muy lejos de las que dan las EVR. Respecto a las otras fases por las que ha pasado esta estadística, parece que el sistema seguido en los periodos 1980-1987 y 1999-2003 subestima en menor medida las migraciones que el situado entre ambos. No obstante, indican un descenso de la migración cuando otras fuentes dan aumentos.

Buena parte de los problemas de la EM pueden estar asociados a la forma en que se selecciona la muestra de la EPA. Diversos trabajos que se han ocupado de 
aspectos metodológicos de esta encuesta recogen las principales características del muestreo tal como lo exponen los documentos del INE. A nuestros efectos, lo fundamental es que es bietápico, de modo que las secciones censales son las unidades muestrales primarias y las viviendas principales, las unidades secundarias. Curiosamente, ni en la documentación del INE ni en estos artículos se menciona el origen del listado de viviendas principales de donde se extrae la muestra. En una somera revisión, solo hemos encontrado un trabajo donde se señala que los hogares, que se identifican con viviendas principales, son «de hecho, direcciones postales» (Jiménez-Martín y Peracchi, 1999). Desde nuestro punto de vista, hay que resaltar que esas direcciones se extraen de las viviendas que el padrón de habitantes da como ocupadas. Es decir, la EPA no muestrea viviendas para luego realizar la encuesta en las ocupadas principales que aparezcan, sino que parte de una relación de estas viviendas supuestamente principales derivada del padrón.

Nuestra hipótesis es que la encuesta, al elaborar la muestra sobre las viviendas ocupadas según el padrón, se ve afectada para el estudio de las migraciones por los problemas que pueda tener el padrón a este respecto. Las migraciones no se registran en el padrón de forma inmediata. Debemos dar por seguro que, entre el momento en que se produce el cambio de residencia y el momento en que se registra en el padrón, transcurre un periodo de tiempo variable, que es función, sobre todo, de las necesidades que tenga la familia de figurar en ese registro administrativo. Ya hemos señalado que las EVR recogen el hecho administrativo del alta y la baja, que se deriva (o no) de una migración, no la migración misma. Al muestrear sobre las viviendas ocupadas, la EPA deja fuera de su universo real las viviendas realmente ocupadas, pero que aun no aparecen como tales en el padrón porque sus habitantes aun no se han dado de alta, al mismo tiempo que da por ocupadas viviendas que ya han sido dejadas por sus anteriores residentes y en el momento de la encuesta habrán vuelto, o no, a ser ocupadas. Si suponemos que el periodo medio que deja pasar una familia entre el momento en que se muda y aquel en el que se da de alta en el nuevo municipio es de seis meses, tendríamos que solo la mitad aproximada de los migrantes aparecerían en la muestra. Un sencillo cálculo nos dice que son poco más de la mitad (55\%) las altas en el primer año tras la renovación del padrón respecto a los años que podemos considerar más cercanos a la normalidad (los que van del tercero al quinto) ${ }^{2}$. La hipótesis de que el retraso medio para empadronarse ronda el medio año después de la migración efectiva, no debe estar lejos de la realidad. Por tanto, cualquier muestra basada en el padrón deja fuera las viviendas que hayan sido ocupadas más recientemente, es decir, buena parte de los hogares de los migrantes que la EM pretende estudiar.

No hemos encontrado una consideración sobre esta cuestión en la literatura que trata de la EM. Sin embargo, los problemas que plantea el padrón para seleccionar las unidades a entrevistar son conocidos y de nuevo se han planteado para la Encuesta Nacional de Inmigrantes de 2007 (Reher y Requena,

2. Aunque ese porcentaje no ha permanecido constante: era más alto el año siguiente al padrón de 1965, bajó hasta un 42\% en 1981 y volvió a subir hasta el 65\% el año del padrón de 1996. 
2009). Encuesta que, por centrarse en la situación de los inmigrantes extranjeros, no forma parte de las fuentes que aquí estamos estudiando.

Con independencia de las dificultades asociadas a la estimación para dominios pequeños (Martí y Ródenas, 2004), creemos que el principal problema de esta encuesta reside en la forma de selección de la muestra de la EPA. Esto supone, por otra parte, que la EPA tiene un cierto sesgo en la investigación de su propio objeto: la actividad y el paro. Sesgo que se deriva de que, en la muestra, están infrarrepresentados los individuos y familias de movilidad más reciente y los más móviles. Aunque no sea este el objeto del artículo, debemos señalar que posiblemente, en la medida en que esta movilidad esté asociada a la búsqueda y al cambio de trabajo, la EPA no estima adecuadamente actividad, ocupación y paro.

En conclusión, ninguna de las fuentes disponibles permite analizar la evolución año a año de las migraciones en el largo plazo. En el corto o medio plazo, y solo a partir de finales de los años noventa, la EVR podría ofrecer una base más sólida para analizar la evolución anual, pero de nuevo surgen algunas dudas que se tratarán más adelante.

\section{La evolución de las migraciones por décadas, desde 1961 hasta la actualidad}

Algunas de las líneas generales de la evolución de las migraciones interiores en el largo plazo son fáciles de establecer y sobradamente conocidas, pero otras no son tan evidentes y, en todo caso, es difícil cuantificar con precisión dicha evolución. La razón de esta dificultad está en la disparidad de los flujos migratorios ofrecidos por las distintas fuentes disponibles y en las resistencias que éstas imponen al análisis demográfico al uso, aunque no se trata de un problema que afecte exclusivamente a nuestro país. Por eso, la siguiente tarea es comparar las fuentes por periodos suficientemente amplios, ya que en la evolución anual es imposible de realizar. Las fuentes mismas nos imponen un análisis por decenios. Utilizamos la pregunta censal sobre lugar de residencia a una fecha fija anterior, la pregunta sobre la última migración (en censos y padrones), además de la encuesta, las EVR y la ESD. Un primer acercamiento, en números absolutos anuales medios de migraciones y migrantes según se derivan de estas fuentes ${ }^{3}$, se recoge en la figura 3.

La fuente más homogénea y estable en el tiempo es la pregunta censal sobre la residencia a una fecha fija anterior (en las figuras aparece como «censo anterior»). Dibuja un progresivo descenso de las migraciones interiores en las cuatro décadas para las que tenemos datos, a falta de lo que diga el nuevo

3. Para calcular las medias anuales, se ha tenido en cuenta que la distancia entre los censos no siempre es de diez años exactos, puesto que a veces es algo mayor. Además, era obligado presentar medias anuales, porque, de algunas fuentes, no disponemos de las cifras de determinados años. Por último, aunque centrado el análisis en décadas que acaban en años terminados en cero, en realidad, los periodos a que se refieren los tres últimos censos terminan en años acabados en uno. 
Figura 3. Evolución de las migraciones interiores por decenios según distintas fuentes

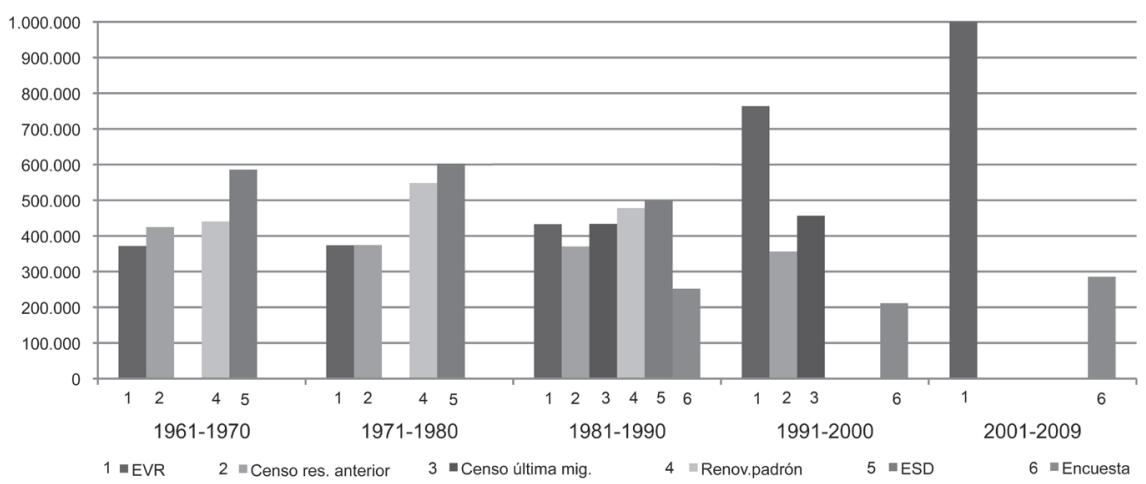

Fuente: elaboración propia a partir de las fuentes citadas en figuras 1 y 2 y de la Encuesta Sociodemográfica (INE, 1993b).

censo de 2011. Sin embargo, las EVR arrojan un pequeño descenso entre los años sesenta y los setenta, para describir luego un enorme aumento en las dos últimas décadas.

Pero, en la figura 3, no pretendemos tanto comparar la evolución de las migraciones según cada una de las fuentes, como comparar las distintas fuentes en cada periodo. De ahí el modo en que está dispuesta.

Como cabía esperar, la pregunta censal sobre la última migración arroja cifras superiores a la pregunta sobre la residencia en una fecha anterior. Es lógico, la primera se dirige a toda la población, la segunda solo a los mayores de diez años. Además, en esta, algunos movimientos pueden no dejar huella cuando se hacen dos migraciones y la última devuelve a sus protagonistas al punto de partida. Lo que llama la atención es un tema sobre el que volveremos, que la relación entre ambas cantidades es mayor según el censo de 2001 que según el de 1991: 1,28 frente a 1,17.

Se han incluido en el gráfico los resultados de las preguntas sobre la última migración de las renovaciones del padrón de 1975 y 1986, sin límite temporal en su formulación, pero que se ajustan mal al análisis por decenios que aquí hacemos. Como este tipo de preguntas privilegian los movimientos más recientes, las del periodo 1961-1970 (del padrón de 1975) recogen relativamente menos migrantes. En el periodo 1981-1990 aparecen en la figura la media de los cinco primeros años de la década (a partir del padrón de 1986), que, por la misma razón, tiende a sobreestimarla. Mientras que en el periodo 1971-1980 se recoge una media calculada a partir de los dos padrones (1975 y 1986), que, sin embargo, parece sobreestimar los movimientos.

Como ya se dijo, la ESD de 1991 es una encuesta retrospectiva que preguntó por todas las migraciones de los encuestados a lo largo de sus vidas. El número de migraciones está condicionado por el hecho de que no se recoge información correspondiente a quienes ya no estén en el universo investigado: 
los fallecidos y los residentes fuera de España. Por tanto, tenderá a subestimar el total de migraciones más antiguas. A pesar de ello, da la cifra más alta en los tres decenios para los que se ofrecen estimaciones, aunque la relación con los datos censales referidos a la residencia a una fecha anterior no es estable: $1,38,1,65$ y 1,35 migraciones por cada migrante, respectivamente.

Las EVR son las únicas estadísticas presentes a lo largo de los cinco periodos considerados. En comparación con las demás fuentes, parece evidente que, durante los años sesenta y setenta, su cobertura era insuficiente, algo de lo que ya se era consciente en esos años (Ros Jimeno, 1968). Si separamos los datos para los siguientes dos quinquenios, veremos que, en el periodo 1981-1985, todavía tenderían a la subestimación, mientras que en 1986-1990 ya no sería así. Por tanto, como otros autores han hecho notar (Puyol, 1997), a partir de mediados de los años ochenta, las EVR presentan una cobertura considerablemente mayor de las migraciones. La democracia y el desarrollo de los servicios del estado de bienestar supondrían nuevos alicientes para que los ciudadanos se preocuparan de empadronarse en el lugar en el que residen.

Respecto a la EM, los datos de los ochenta y los noventa, en comparación con el censo, reflejan la misma tendencia a la disminución. El problema es que la cuantía de las migraciones que detectan es muy inferior. En la década siguiente, solo podemos comparar sus resultados con la EVR, con la que coinciden al señalar la tendencia al incremento de las migraciones, aunque de nuevo se da a unos niveles mucho más bajos. No obstante, en el punto anterior, vimos que, en la evolución anual de las migraciones, la EM no coincidía con las EVR; por tanto, no debemos ahora concluir que estiman bien las tendencias aunque no estimen bien las magnitudes.

De todas formas, la comparación de las magnitudes absolutas de migraciones y migrantes de las distintas fuentes se enfrenta a notables obstáculos, puesto que no afecta a los mismos volúmenes de población. En el caso de las EVR, se refiere a toda la población del país en un periodo considerado; en las preguntas retrospectivas de censos y encuestas, a la población superviviente y presente en el momento de la recogida de datos; en la pregunta sobre el lugar de residencia en la fecha del censo anterior, a la población que estuviese presente en ese momento (lo que no incluye a los que entonces aun no habían nacido ni a los que vivían en el extranjero). Es necesario, por tanto, calcular tasas ${ }^{4}$ teniendo en cuenta los distintos efectivos que han de ponerse en el denominador en función de las características de los flujos o efectivos del numerador. En la figura 4 , se recogen tales tasas ordenadas de forma diferente que en la figura 3 para resaltar la evolución por periodos, más que la comparación entre las fuentes dentro de cada periodo. Además, se obvian las renovaciones del padrón y se

4. En realidad, en términos demográficos, solo son tasas cuando dividimos flujos de acontecimientos (migraciones) entre efectivos medios, forma de cálculo que solo se emplea en el caso de las EVR y la EM. En los censos, calculamos proporciones, puesto que, en el numerador, utilizamos efectivos de migrantes y, en el denominador, efectivos de población susceptible de haber migrado. 
Figura 4. Tasas de migración interior, por ámbito de la migración y decenios, según distintas fuentes

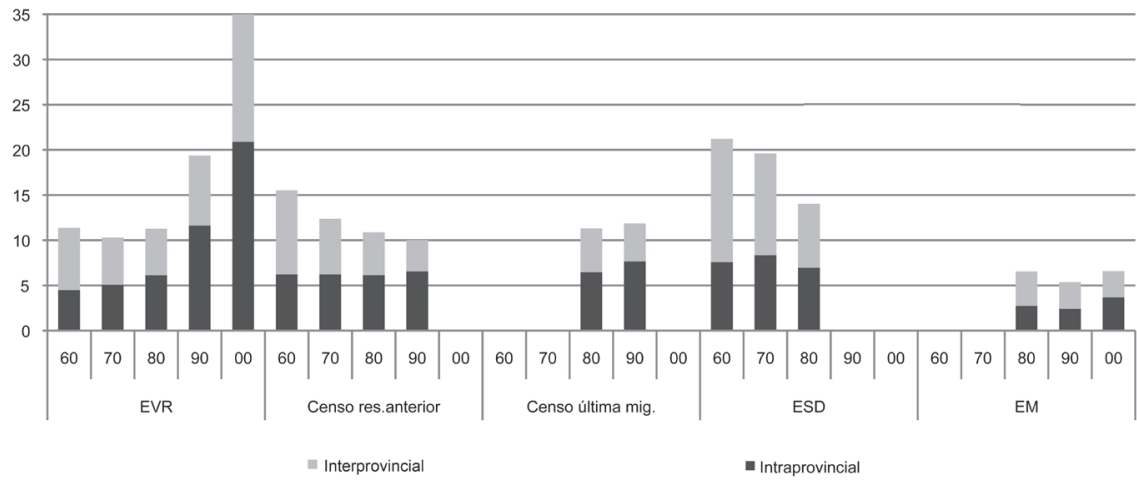

Fuente: elaboración propia a partir de las fuentes citadas en las figuras 1 a 3 .

añade nueva información, al distinguir entre migraciones intraprovinciales e interprovinciales.

Parece evidente que, en los años sesenta y los primeros setenta, las migraciones interiores alcanzaron volúmenes enormes que luego descendieron. Resulta una conclusión lógica si tenemos en cuenta el extraordinario proceso de transformación social que afectó a la sociedad española, como consecuencia del crecimiento económico acelerado, pero profundamente desigual en su distribución territorial. Es una conclusión de sentido común, corroborada por el conocimiento que toda una generación tiene de innumerables experiencias de esperanzas, desarraigos, frustraciones y éxitos ligadas a la migración. Es también una conclusión corroborada por las estadísticas, aunque no por todas.

Las EVR, en contradicción con las demás fuentes, no recogen de la misma forma tal descenso de la migración en las tres primeras décadas analizadas. Debemos concluir que, en el largo plazo, las EVR no permiten analizar la evolución de las migraciones. Sin duda porque su cobertura, como ya se ha señalado, no ha permanecido constante.

Otra conclusión se deriva de la comparación entre las tasas de la ESD, que recoge migraciones, y las tasas calculadas a partir de la pregunta censal sobre la residencia anterior. Si damos por buenas las estimaciones de la ESD, debemos deducir que los migrantes interprovinciales hacen más migraciones (entre un 47 y un $83 \%$ más según la década) que los migrantes intraprovinciales (entre un 13 y un 34\% más). En ambos casos, el porcentaje es mayor en la década de los setenta que en la anterior y la posterior. Podría ser un efecto meramente estadístico, pero hay razones para pensar que también podría deberse a las características de la década de los setenta. En esta se suceden dos periodos diferentes, uno continuación del ciclo migratorio anterior, de predominio de migraciones de larga distancia impulsadas por motivos laborales, y otro derivado del cambio en el ciclo económico que se produce mediada la década, donde 
predominan las migraciones de retorno. La confluencia en el mismo periodo de salidas y retornos, con una posible reducción del periodo de migración, conduciría, así, a explicar el mayor número de migraciones por migrante. Hay que tener en cuenta que algunos de estos migrantes salidos y retornados al mismo municipio durante la década serían invisibles para la pregunta sobre la residencia anterior, en 1970.

Lo que resulta menos evidente es lo que ha ocurrido posteriormente. Algunas fuentes parecen indicar que esas migraciones no se vuelven a recuperar completamente en los noventa, mientras que otras indican un nuevo ciclo migratorio interior de una intensidad desconocida, incluso muy superior a los años sesenta. Entre las primeras, está la pregunta sobre la residencia en una fecha anterior del censo de 2001, que indica disminución. Sin embargo, la evolución de la tasa calculada a partir de la última migración indica cierto crecimiento. Un análisis cruzando ambas preguntas en cada censo y observando el cambio entre los dos periodos ${ }^{5}$, resulta clarificador.

En el cuadro 2, se recogen las no coincidencias entre las cifras de migrantes de ambas preguntas que fueron, durante el periodo intercensal de 1991-2001, de 4.872.136 según la última migración y de 3.800.409 según la residencia en 1991; una diferencia de algo más de un millón de migrantes (mientras que en el censo anterior era de poco más de 600.000) ${ }^{6}$. La mayor parte se explica por las migraciones interiores de corta duración con retorno al municipio de partida, que, por tanto, no aparecen como migrantes en la pregunta sobre la residencia en 1991, que se eleva a 647.514 personas. En relación con el censo de 1991, se habían duplicado holgadamente, por lo que también es el factor que en mayor medida explica el aumento de estas diferencias entre ambos censos.

Por supuesto, la presencia de los que, en 1991, aún no habían nacido es otro componente importante, pero es el que menos crece en relación con el censo de 1991 (son 396.339 y crecen un 24\%). Las demás celdas de la tabla recogen discrepancias en el ámbito de la migración. Varios miles de personas aparecen como migrantes interiores en una de las preguntas y no en la otra. Un total de 110.208 que vivían en el extranjero en 1991 pero que posteriormente, tras su llegada a España, hicieron una migración interior. Otras 82.334 personas que vivían en España en 1991 pero cuya última migración las trajo de vuelta del extranjero. Ambos casos indican una fuerte movilidad de corta duración que aumenta mucho en comparación con el censo de 1991. Lo mismo que otros 110.162 migrantes que vuelven a otro municipio de la misma provincia habiendo pasado por otra provincia; aunque, en este caso, el incremento es menor.

El aumento de la diferencia entre el total de migraciones internas deducidas de la última migración y las deducidas del lugar de residencia unos diez

5. Este análisis se puede hacer utilizando la aplicación que el INE ha puesto a disposición de los usuarios para acceder a los resultados del censo de 2001. Respecto al de 1991, es necesario explotar los microdatos, también accesibles en la página del INE.

6. En el cuadro 2, se recogen entre paréntesis los porcentajes de variación que suponen estas cifras respecto al cruce de las mismas variables según el censo de 1991. 
Cuadro 2. Diferencias en el número de migrantes en las dos preguntas censales, según el censo de 2001, en números absolutos y porcentaje de aumento respecto al censo de 1991

\begin{tabular}{lrrrr}
\hline $\begin{array}{l}\text { Relación entre } \\
\text { residencia en el } \\
\text { censo anterior }\end{array}$ & \multicolumn{3}{c}{$\begin{array}{c}\text { Relación entre residencia anterior y actual } \\
\text { (pregunta última migración) }\end{array}$} \\
\cline { 2 - 5 } y actual & $\begin{array}{c}\text { Misma } \\
\text { provincia }\end{array}$ & $\begin{array}{c}\text { Distinta } \\
\text { provincia }\end{array}$ & Extranjero & Total \\
\hline No había nacido & $\begin{array}{r}259.125 \\
(+41 \%)\end{array}$ & $\begin{array}{r}137.214 \\
(+1 \%)\end{array}$ & 396.339 \\
& 415.170 & 232.344 & & $(+24 \%)$ \\
Mismo municipio & $(+237 \%)$ & $(+53 \%)$ & & 647.514 \\
& & 110.162 & 44.793 & \\
Misma provincia & & $(+165 \%)$ & $(+649 \%)$ & \\
& $(-27 \%)$ & & 37.541 & \\
Distinta provincia & 61.826 & 48.382 & & \\
& $(+201 \%)$ & $(+192 \%)$ & & $(+346 \%)$ \\
Extranjero & 810.453 & 528.102 & 82.334 & 1.420 .889 \\
& $(+88 \%)$ & $(+53 \%)$ & $(+472 \%)$ & $(+80 \%)$ \\
\hline Total & & & & \\
\hline
\end{tabular}

Fuente: elaboración propia a partir de los censos de 1991 y 2001.

Nota: Se han dejado en blanco las celdas que no participan en las migraciones interiores de ambas preguntas censales, así como aquellas en que las dos preguntas clasifican por igual a los migrantes.

años antes se debe, por tanto, al aumento de la movilidad de corta duración, que afecta a migraciones de larga distancia pero también intraprovinciales. Puesto que la pregunta por la residencia anterior registraba un descenso de los migrantes, podría decirse que hay menos migrantes pero que se mueven más. Podemos concluir, además, que la pregunta por el lugar de residencia diez años antes recoge cambios más estructurales, mientras que la pregunta por la última migración es más sensible a los más coyunturales.

En cualquier caso, son las EVR las que señalan un enorme aumento de las migraciones interiores, pero es de tal envergadura que no podemos darlo por bueno sin analizar más detalladamente los factores que podrían explicarlo. A lo que dedicamos el próximo apartado, a la espera de los resultados del censo que se realizará este mismo año, pero cuyos datos no estarán disponibles hasta más adelante.

No obstante, la figura 5 nos permite apreciar mejor cómo se reparten migraciones intraprovinciales e interprovinciales a lo largo de los decenios estudiados, al expresar las tasas sobre el total de la movilidad migratoria. Todas las fuentes coinciden en que las migraciones de corta distancia, las intraprovinciales, han ganado presencia en detrimento de las de larga distancia, con la excepción de la EVR, que nos indica que este proceso se ha detenido durante la primera década del siglo XxI. 
Figura 5. Distribución por ámbito de las tasas de migración interior, por decenios, según distintas fuentes

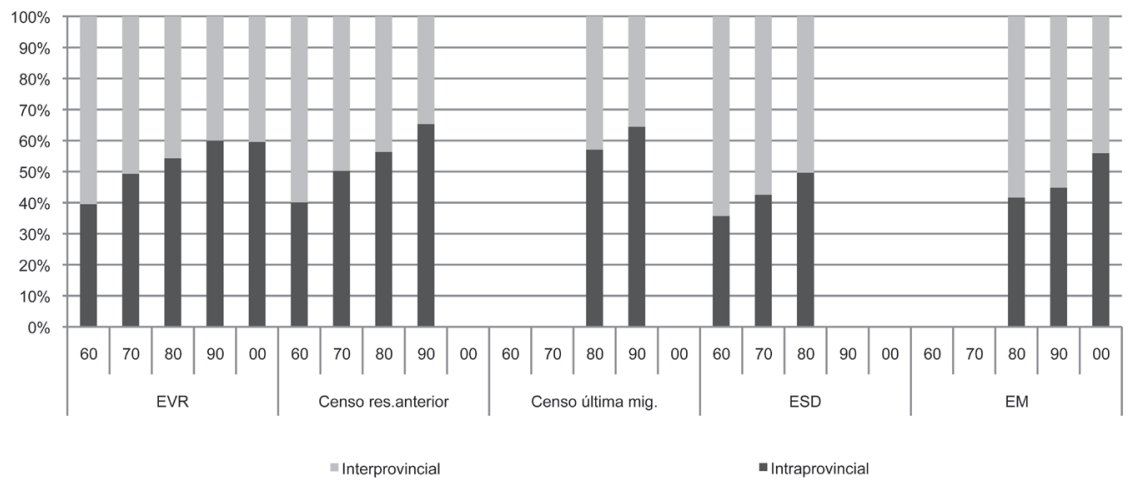

Fuente: elaboración propia a partir de las fuentes citadas en las figuras 1 a 3.

Además, se pueden observar otras dos particularidades destacables. La primera es que la EM parece recoger mejor las migraciones interprovinciales que las intraprovinciales. Si nuestra hipótesis sobre el origen de la infraestimación de las migraciones por esta fuente es cierta, podría deberse a que unos u otros migrantes tienen pautas de empadronamiento distintas y, por tanto, probabilidades diferentes de estar en el universo sobre el que se construye la muestra. La segunda es que las dos preguntas censales, sobre la última migración y sobre la residencia a una fecha fija anterior, parecen dar resultados equivalentes.

\section{4. ¿Se debe todo el incremento de la movilidad que reflejan las EVR a la mayor presencia de extranjeros?}

Hay diversos factores que indican que la movilidad ha crecido realmente en la primera década del siglo xxi. Sin embargo, la magnitud de ese incremento en las EVR es enorme y cabe preguntarse si es posible que las migraciones interiores en España hayan aumentado en los primeros años del siglo XXI tanto como dicen estas estadísticas. Antes subestimaban las migraciones - algo que está demostrado- , pero pudiera ser que ahora tiendan a sobreestimarlas. En algún momento, las EVR habrán tenido que pasar de la subestimación a una correcta estimación o, en el peor de los casos, a la sobreestimación, con independencia del seguro desfase entre la migración misma y el acto administrativo del alta padronal.

Valorarlo es difícil, puesto que, para los últimos años, no hay más fuentes que las EVR y la EM. Como esta es inutilizable a estos efectos, debido a su crónica subestimación de la movilidad, debemos partir del análisis comparativo en momentos anteriores, a la espera de que estén disponibles los datos del censo de 2011. 
Las tasas brutas de migración están afectadas por la estructura por edades y sexo y por la distinta probabilidad de migrar por edades. Pero siendo ésta una proposición aplicable a todo tipo de fenómenos demográficos, las relaciones entre estructuras demográficas, intensidad y determinantes socioeconómicos en la migración es distinta a la de fecundidad o mortalidad. Al cambiar la estructura por edades de la población española, cambiará el volumen de las migraciones. Para deshacernos de estos efectos, no podemos calcular índices sintéticos de migración con todas las fuentes, como se hace para estudiar la evolución de la fecundidad. Podemos hacerlo con las EVR y también con algunos censos, mediante la pregunta sobre el lugar de residencia un año antes en el censo de 1991, y explotando la información sobre los llegados al municipio en el último año (última migración) en el censo de 2001.

En la figura 6, se pueden ver las tasas específicas de migración según estas fuentes ${ }^{7}$. Aunque elaboradas de distinta forma, las de los censos para $1990 \mathrm{y}$ 2001 son parecidas y coherentes con lo que ya hemos visto. Sin embargo, las EVR de 2001 son mayores que las del censo del mismo año, a pesar de que, en ese año, tales estadísticas registraron una pequeña inflexión a la baja, como se vio en el apartado 2. Diferencias que están afectadas por cuestiones metodológicas, derivadas de las fuentes y de la forma de cálculo, pero que no se reducen a ellas. Ambas fuentes recogen de forma distinta la realidad migratoria y una de ellas, al menos, debe hacerlo mal.

En otro lugar (Feria et al., 2008), ya hemos señalado que, dado que las EVR registran migraciones y los censos migrantes, la relación entre ambas informaría sobre el número de migraciones que haría de media cada migrante durante ese año, pero no parece posible que, en 2001, cada migrante haga de media entre 1,3 y 1,8 migraciones, dependiendo del grupo de edad. El número de migraciones debe parecerse mucho al número de migrantes cuando el periodo analizado es suficientemente corto, como es el caso del cuadro, de tan solo un año ${ }^{8}$. Según la Encuesta Sociodemográfica de 1991, el número de migraciones por migrante era de 1,8 a lo largo de la vida. Por tanto, la relación entre EVR y censo es imposible. Algunos autores han comparado los datos de migraciones del censo de 2001 y de las EVR, partiendo de la base de que estas últimas son las estadísticas de referencia y llegando a la conclusión de que el

7. Para las EVR, calculamos verdaderas tasas demográficas con acontecimientos en el numerador y efectivos a mitad del periodo en el denominador. Para los censos, en realidad, calculamos proporciones de migrantes sobre la población susceptible de haber migrado al final del periodo, es decir, a esta hay que deducirle la población que vive en viviendas colectivas, la que no había nacido (diferente en los censos de 1991 y 2001, dado que la pregunta es diferente, pero que en todo caso limita el primer grupo a la población de uno a cuatro años cumplidos) y la que vivía en el extranjero.

8. En realidad, en el censo, solo es de diez meses, ya que recoge las migraciones en el último año, el 2001, cuando el censo tenía fecha de referencia a 1 de noviembre. Por esa razón, hemos tenido que multiplicar los migrantes por 1,2 para estimar las migraciones correspondientes a un año completo. 
Figura 6. Tasas de migración por edad en varios años, según distintasfuentes

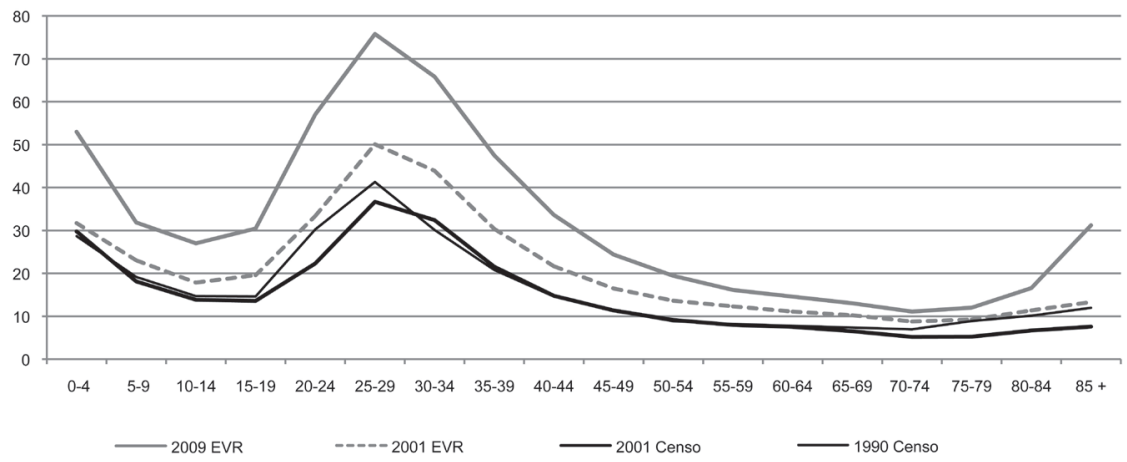

Fuente: elaboración propia a partir de microdatos de las EVR y los censos de 1991 y 2001.

censo no es fiable al respecto (Ródenas y Martí, 2009a) ${ }^{9}$. Pero, aunque el censo de 2001 subestimase a los migrantes, no está claro por qué se han de tomar las EVR como fuente de referencia. Además, con posterioridad, las EVR siguen mostrando un fuerte crecimiento de las migraciones, que debe ser analizado antes de darlo por bueno.

Al comparar los años 2001 y 2009, se advierte un extraordinario incremento de las tasas de migración, derivadas de las EVR, a casi todas las edades. Puesto que las pautas de migración interna de los extranjeros son superiores a las de los españoles, podría ser que ese aumento se debiese únicamente a la mayor presencia de población extranjera. Para comprobarlo, calculamos las tasas específicas por edades de españoles y extranjeros en ambos momentos, para ver su evolución (figura 7).

Vemos que el incremento en las pautas de migración por edades ha sido desigual, más importante en algunos grupos de edad en ambos colectivos (los niños) y en los españoles jóvenes (entre 20 y 40 años), pero especialmente en los extranjeros. Por tanto, el incremento en las tasas generales de migración de la figura 6 debe ser consecuencia, sobre todo, del mayor peso de los extranjeros en el conjunto de la población. Aunque hay que advertir que la población extranjera no tiene mayor movilidad por su propia "naturaleza», sino por las condiciones en las que vive y busca su lugar en un país nuevo. Por eso, es de esperar que su movilidad tienda a reducirse según se va adaptando al país, como ya señalan algunos estudios específicos sobre la inmigración extranjera (Pérez Yruela y Rinken, 2005). Si se mantiene este efecto, es porque la mayor parte de esa población extranjera lleva relativamente poco tiempo en España.

9. Algunas de las incoherencias señaladas por las autoras podría interpretarse de forma más favorable al censo de 2001; además, en otros trabajos (Ródenas y Martí, 2006, 2009b), matizan estas conclusiones al comprobar que las migraciones repetidas en cortos periodos de tiempo en las EVR podrían explicar parte de las diferencias señaladas. 
Figura 7. Tasas de migración por edad de españoles y extranjeros en 2001 y 2009, según EVR

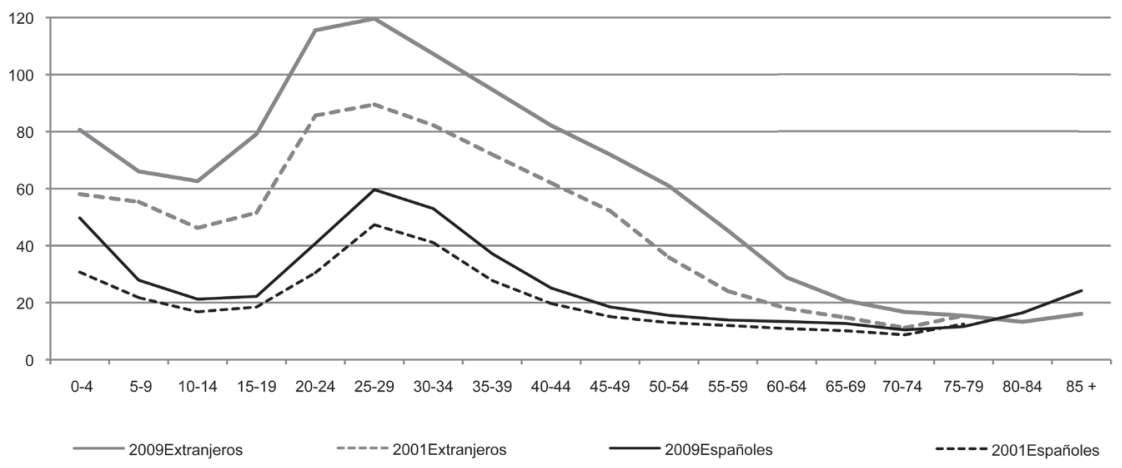

Fuente: elaboración propia a partir de microdatos de las EVR.

El último cuadro intenta resumir los principales determinantes demográficos de la evolución del volumen de migraciones internas en España a lo largo de los cinco decenios analizados. Se ha calculado el número de migraciones estandarizadas para todos los años utilizando las tasas de migración de los españoles en el periodo 2008-2009 y las estructuras de edades y sexos de cada año ${ }^{10}$. Para los dos últimos decenios, se han comparado las migraciones que los extranjeros presentes en España tendrían con las tasas de los españoles y con las propias de los extranjeros en el mismo periodo. En las primeras filas, aparecen los porcentajes en que afectarían los distintos factores al volumen de migraciones o a las tasas brutas. En las filas de más abajo, aparecen las tasas calculadas con las migraciones estandarizadas y las tasas derivadas de cada fuente. Al final, se incluye el porcentaje de diferencia entre las estandarizadas y la más alta de estas últimas.

Por una parte, el mero incremento de la población haría aumentar las migraciones. Es el efecto del tamaño que, como es obvio, solo afecta cuando comparamos números absolutos, pero no tasas brutas. Por otra parte, el efecto de la estructura de edades en el caso de la migración es relativamente pequeño. Solo haría aumentar el volumen de migrantes y, por tanto, también las tasas, en un $5 \%$ en los años sesenta; pues durante los decenios posteriores el efecto es muy pequeño. Por último, el efecto del aumento de la presencia de un colectivo especialmente móvil en comparación con el resto, la población extranjera, sí tiene un efecto importante en los últimos decenios (los únicos para los que tiene sentido calcularlo).

Lo que no expliquen la acción conjunta de estos tres factores se debe a cambios en las pautas de movilidad interna de los españoles debido a otros determinantes. En primer lugar, la transformación de los sistemas urbanos con

10. Se han empleado las estimaciones de población intercensal y de población actual, realizadas por el INE y disponibles en su página web. 
Cuadro 3. Cálculo de los efectos de las variables demográficas sobre el volumen y las tasas brutas de migración

$1961-1970 \quad 1971-1980 \quad 1981-1990 \quad 1991-2000 \quad 2001-2009$

Efectos en tantos por cien:

Tamaño de la población

Estructura de sexo y edades

Población extranjera

$5-2$

$-22 \quad-16 \quad-13$

$3-5$

Tasas en tantos por mil:

Estandarizadas

Según EVR

Según censo residencia anterior

16

Según censo última migración

- $\quad$ - 11

Según ESD

Diferencia con la más alta en \%

Fuente: elaboración propia.

el desarrollo y la extensión del fenómeno metropolitano desde los años ochenta, lo que explicaría buena parte del incremento en la movilidad de más corta distancia, la intraprovincial (Feria y Susino, 2006). En segundo lugar, la sucesión de los ciclos migratorios ligados a los ciclos económicos y a las transformaciones estructurales de la economía y las ocupaciones, que estaría en la base del descenso de las migraciones interprovinciales en el pasado y su posible incremento en el presente. En tercer lugar, la emergencia de nuevas formas de migración ligadas a transformaciones territoriales más allá de los espacios metropolitanos, vinculadas a nuevas formas de producción espacialmente menos concentradas y a nuevos tipos de consumo del territorio (Solana, 2005).

Que todos estos factores hagan que la propensión a migrar haya crecido en casi un $50 \%$ en la actualidad respecto a los años sesenta y setenta o se haya duplicado respecto a los ochenta, es difícil de creer. Es verdad que la presencia de la población extranjera, con más alta movilidad, hace aumentar las tasas y que otros factores pueden haber incidido en la más alta movilidad de los españoles, pero difícilmente hasta ese punto.

Nuestra hipótesis es que no todo ese crecimiento responde a un incremento real de la movilidad, sino que, en parte, se debe a un cambio en el registro estadístico y administrativo. Las EVR han experimentado abundantes cambios metodológicos. Desde su creación, los movimientos internos se contabilizaban a partir de las relaciones numéricas enviadas por los ayuntamientos al INE. En 1980, se empieza a contar la inmigración procedente del extranjero. En 1988, se informatizan los documentos de alta y baja padronal, lo cual permite mayor depuración de los datos. En 1996, se establece el nuevo sistema de gestión continua del padrón, con ello se obtienen los datos nominativos directamente de los 
ficheros remitidos por los ayuntamientos al INE. En 2001, la estadística se obtiene directamente por el INE a partir de su propia base padronal, por comparación con el municipio de residencia anterior que consta en dicha base y con independencia del municipio de residencia anterior que declare el interesado. En 2004, se incluyen también en las EVR las altas por omisión y las bajas por inclusión indebida de extranjeros correspondientes a inmigraciones y emigraciones del exterior. En 2006, se empieza a aplicar la modificación legislativa de 2003 sobre la obligación de los extranjeros no comunitarios sin autorización de residencia permanente de renovar su inscripción padronal cada dos años; para los que no lo hagan, se declara la caducidad de la inscripción, pero no se contabilizan como salidas en la EVR. En cualquier caso, las EVR no registran la totalidad de las altas y las bajas por cambio de residencia, solamente las recibidas con anterioridad al 1 de marzo de cada año, aunque el INE reciba ficheros de variación con movimientos realizados meses e incluso años antes. Podría, por tanto, haber incluso cierto subregistro, a pesar de todas las mejoras introducidas en la gestión de altas y bajas.

Pero el problema fundamental parece residir más bien en el uso que los ciudadanos hacen del padrón. Si antes las EVR subestimaban las migraciones y poco a poco dejaron de hacerlo es porque, desde los años ochenta, hay más incentivos para empadronarse, tanto por la celebración periódica de elecciones, como por la ampliación de los servicios públicos ligados al desarrollo del estado de bienestar. Pero esto también ha impulsado un uso fraudulento del empadronamiento.

En muchos trámites administrativos, es necesario demostrar la residencia mediante el certificado de empadronamiento. Es así para acceder a prestaciones de los sistemas de servicios sociales (ayuda a domicilio, ley de dependencia), para la utilización de servicios y equipamientos municipales (deportivos, por ejemplo), para determinadas prestaciones sanitarias, pero sobre todo en la elección de centro escolar. Desde hace una década, son frecuentes las noticias periodísticas sobre padres que se empadronan en viviendas distintas a aquellas en las que residen ${ }^{11}$, frecuentemente en municipios distintos de las áreas metropolitanas. A esto hay que añadir los falsos empadronamientos por razones fiscales y electorales ${ }^{12}$. Esto último puede suponer una falsa migración entre municipios muy distantes. Los extranjeros tienen razones adicionales para empadronarse, por los derechos que les reconoce la ley al hacerlo y por la expectativa de poder demostrar suficiente arraigo en el país para acceder a un posible permiso de residencia. Esto ha llevado al empadronamiento de

11. En varias ciudades se han detectado numerosos casos de padres han llegado a pagar los servicios de un detective privado para poder demostrar el fraude de otros que, de esa manera, habían dejado a sus hijos sin acceso al colegio de sus preferencias. Se han llegado a detectar parejas que se habían divorciado fraudulentamente y empadronado en viviendas distintas, aunque en realidad sigan unidas y compartiendo vivienda. Una noticia reciente al respecto en El País, edición Madrid, de 19-3-2011.

12. El INE, antes de las elecciones municipales y autonómicas de 2011, ha detectado incrementos «significativos y no justificados» de población en más de dos centenares de municipios españoles (El País, 5-4-2011). 
familiares o amigos que ni siquiera están en el país y que «se mueven» junto a la persona que hace de anfitrión.

Hace años, la certificación de la residencia se hacía previa visita de un funcionario municipal al domicilio del afectado, para constatar, directamente o a través de los vecinos, su situación. Actualmente, es el mero empadronamiento lo que certifica la residencia y ello incentiva este uso fraudulento del padrón. Debemos a Ródenas y Martí (2006, 2009b) un intento de cuantificación de las «falsas migraciones» en las EVR, a través de las migraciones encadenadas de retorno que se producen en intervalos cortos de tiempo en el mismo año o en años sucesivos. En estas migraciones participan más españoles que extranjeros y tienen especial presencia las mujeres y los niños en edad escolar. Aunque, para los años considerados, las autoras indican que su magnitud no pone en cuestión la calidad de las estadísticas, no quiere decir que el fenómeno no sea más amplio y haya seguido creciendo.

Hay indicios, por tanto, de cierta sobreestimación de las migraciones por las EVR, aunque no podemos saber en qué medida. De ahí la importancia que tiene el próximo censo de 2011, cuyo proyecto prevé una amplia batería de preguntas al efecto. El hecho de que el censo de 2011 tenga una base muestral, podría suponer un problema para la estimación de los flujos migratorios entre unidades territoriales de pequeña población, pero no a la escala necesaria para realizar esta contrastación. El problema podría surgir porque el censo tomará el padrón continuo como universo de partida, y los factores de ponderación de la muestra se verán afectados por los posibles errores del padrón, a no ser que se utilice el mismo censo para evaluar y corregir las cifras de población que ofrece el padrón.

\section{Conclusiones}

Algunas de las diferencias entre las distintas fuentes para estudiar las migraciones interiores pueden explicarse por diferencias reales en las pautas migratorias, recogidas de formas diferentes según el instrumento estadístico utilizado. Al nivel de análisis aquí realizado, para el conjunto del país y diferenciando como mucho entre migraciones intraprovinciales e interprovinciales, hay bastante coherencia entre las distintas preguntas censales y la ESD. Las que parecen irreductibles a las anteriores son las EVR y la EM, cuyos problemas tienen un origen común en la gestión del padrón de habitantes.

Desde 1996, el INE ha logrado depurar los padrones en un sentido: evitar las duplicaciones en el empadronamiento en más de un municipio. Sin embargo, quedan otras tareas pendientes, algunas de las cuales ya han sido abordadas, por ejemplo: la baja de los extranjeros que dejan nuestro país, así como la situación de los españoles residentes en el extranjero. Pero hay otras que ni siquiera parecen haberse planteado y que son esenciales para mejorar la estimación que los padrones hacen de la población municipal y para mejorar la calidad de las EVR y la base sobre la que se seleccionan las muestras de algunas de las estadísticas más importantes realizadas por el INE. Nos referimos a que las personas estén empadronadas en el domicilio en que realmente residen. El 
padrón se ha convertido en medio de certificación de la residencia sin que previamente se garantice que responde a la realidad residencial de los ciudadanos. Nos arriesgamos a que el hecho administrativo, el empadronamiento, acabe sustituyendo a la realidad misma, la residencia.

Lo dicho no invalida todo el trabajo realizado con el padrón desde que, en 1996, empezó a gestionarse como padrón continuo. Pero su carácter de registro administrativo siempre ha sometido a tensiones y a la tentación de usos espurios a este instrumento que, sin embargo, es fundamental en nuestro sistema estadístico.

Así las cosas, no se pueden utilizar las EVR para analizar la evolución de las migraciones en el largo plazo. Posiblemente, sí en el corto plazo, pero no sabemos desde cuando. Porque si partíamos de su probado subregistro y desde los años ochenta el número de migraciones prácticamente no ha dejado de crecer hasta 2007, ¿en qué momento se habría alcanzado la fiabilidad de la fuente para analizar la evolución cuantitativa de las migraciones? Y, además, una vez alcanzado ese punto, en lo sucesivo se podría haber visto afectada por el aumento de las falsas migraciones. Las EVR se han revelado como una fuente cada vez más útil para analizar distintos aspectos de las migraciones, pero, por todo lo dicho, no se debería aceptar su validez sin más para analizar la específica cuestión de su evolución cuantitativa.

Para comparar en el largo plazo, entre unas décadas y otras, la única fuente fiable es la proveniente de los censos, a pesar de las dudas de algunos autores. En el muy largo plazo, desde los años sesenta, además, la única disponible es la pregunta sobre el lugar de residencia con ocasión del censo anterior. Estamos de enhorabuena, porque quizás sea, por diversas razones, la mejor fuente de la que disponemos.

Necesitamos seguir mejorando nuestros instrumentos estadísticos, pero, mientras tanto, tenemos que utilizar todas las fuentes y considerar su pertinencia, fiabilidad y validez al hablar de migraciones, sin darlas por sentado. $Y$ debemos hacerlo para cada una de las investigaciones que emprendamos y en función de su objeto y sus objetivos específicos.

\section{Referencias bibliográficas}

Ávila Tapies, Rosalía (1993). «Nueva perspectiva de las migraciones interiores españolas». Anales de Geografía de la Universidad Complutense, 13, 111-126.

Ballester Ros, I. (1978). «Principales características en el ámbito regional de los hogares migrantes en el interior de España y de los retornados del extranjero, periodo 1970-75». Revista de Estudios de la Vida Local, 37 (198), 449-464.

Barbancho, Alfonso G. (1975). Las migraciones interiores españolas en 1961-1970. Madrid: Instituto de Estudios Económicos.

Bell, Martin (2005). «Towards Rigorous Cross-National Comparison of Internal Migration: Who Collects What?». Twenty-Fifth Conference. International Union for the Scientific Study of Population. 18-23 de julio. Tours (Francia).

Bentolila, Samuel (2001). Las migraciones interiores en España. Documento de trabajo 2001-2007. FEDEA 2001. 
Bielza de Ory, Vicente (1987). «Migraciones interiores 1970-85». I Jornadas sobre Población Española, 109-118.

Bover, Olympia y Velilla, Pilar (1997), «Migrations in Spain: Historical background and current trends», Banco de España, Working paper 9909.

Courgeau, Daniel (1988). Méthodes de mesure de la mobilité spatiale: migrations internes, mobilité temporaire, navettes. París: INED.

Cruz Villalón, Josefina; Feria, José María, Fernández Salinas, Víctor; Pedregal, Belén (dir.) (1996). Los movimientos migratorios con origen y destino en Andalucía. 1981-1991. Sevilla: Instituto de Estadística de Andalucía.

Domenach, Hervé y Picouet, Michel (1987). «Le caractère de réversibilité dans l'étude de la migration». Population, 42-3, 469-483.

Egea Jiménez, Carmen; Rodríguez Rodríguez, Vicente; Nieto Calmaestra, José Antonio y Jiménez Bautista, Francisco (2005). La migración de retorno en Andalucía. Granada: Universidad de Granada.

Faura Martínez, Úrsula y Gómez García, Juan (2002). «¿Cómo medir los flujos migratorios?». Papers, 66, 15-44.

Feria, José María y Susino, Joaquín (2006). «La dimensión regional y los nuevos referentes de las migraciones interiores en España». En: Fernández Cordón, J.A.; Leal Maldonado, J. (coords.). Análisis territorial de la demografía española. Madrid: Fundación Fernando Abril Martorell.

Feria, José María; Susino, Joaquín; Pedregal, Belén; Oliveira, Gwendoline de y VAHÍ, Amalia (2008). Migraciones y movilidad residencial en Andalucía. 1991-2001. Sevilla: Instituto de Estadística de Andalucía.

Galdós, Rosario y Ruiz Urrestarazu, Eugenio (2001). «Las migraciones interiores en la Comunidad Autónoma del País Vasco a finales del siglo XX». Lurralde: Investigación y Espacio, 24, 295-304.

García Abad, R. (2002). "La decisión de emigrar y el papel de las Redes Migratorias en las migraciones a corta y media distancia». Geo Critica / Scripta Nova. Revista Electrónica de Geografía y Ciencias Sociales, 94 (11).

García Barbancho, Alfonso (1967). Las migraciones interiores españolas. Madrid: Instituto de Desarrollo Económico.

García Coll, Arlinda (2005). «Migraciones interiores y transformaciones territoriales». Papeles de Economía Española, 104, 76-91.

García Coll, Arlinda y Pujadas, Isabel (1995). "Migraciones interiores en España: tendencias recientes y perspectivas de futuro». Revista de Geografia, XXIX (3), 9-148.

García Coll, Arlinda y Stillwell, John (2000). «Internal migration and regional population dynamics in Europe: Spain case study». Working Paper, 2000/08. Universidad de Leeds.

García Coll, Arlinda y Sánchez Aguilera, Dolores (2001). «Las estadísticas demográficas españolas: entre el orden y el caos». Boletín de la AGE, 31, 87-109.

INE (1974). Censo de la Población de España. 1970. Tomo III: Características de la Población. Madrid: Instituto Nacional de Estadística.

- (1977). Padrón Municipal de Habitantes. 1975. Resultados Nacionales. Madrid: Instituto Nacional de Estadística.

- (1985). Censo de Población. 1981. Tomo I, volumen 1: Características de la Población. Resultados Nacionales. Madrid: Instituto Nacional de Estadística.

- (1987). Padrón Municipal de Habitantes. 1986. Resultados Nacionales. Madrid: Instituto Nacional de Estadística. 
INE (1991a). Migraciones. Quinquenio 1961-1965. Madrid: Instituto Nacional de Estadística.

- (1991b). Migraciones. Quinquenio 1966-1970. Madrid: Instituto Nacional de Estadística.

- (1992). Migraciones. Quinquenio 1976-1980. Madrid: Instituto Nacional de Estadística.

- (1993a). Migraciones. Quinquenio 1981-1985. Madrid: Instituto Nacional de Estadística.

- (1993b). Encuesta Sociodemográfica 1991. Tomo II: Resultados Nacionales. Volumen 2: Movimientos Migratorios y Vivienda. Madrid: Instituto Nacional de Estadística.

- (1993c). Censo de Población. 1991. Tomo IV: Resultados Nacionales. Madrid: Instituto Nacional de Estadística.

- (2002). Encuesta de Migraciones. Metodología EPA-2002. Madrid: Instituto Nacional de Estadística.

- (2004). Censos de Población y Vivienda. 2001. Resultados definitivos. Madrid: Instituto Nacional de Estadística. [http://www.ine.es/censo/es/inicio.jsp]

- (2008). Encuesta de Migraciones. Metodología. Madrid: Instituto Nacional de Estadística.

- (varios años). Encuesta de Población Activa. EPA. Encuesta de migraciones. 1980 a 1997. Madrid: Instituto Nacional de Estadística.

- (varios años). Anuarios estadísticos. Madrid: Instituto Nacional de Estadística.

Jiménez-Martín, Sergi y Peracchi, Franco (1999). «La calidad de la EPA en la estimación de las transiciones en el mercado de trabajo». Ekonomiaz, 43, 158-187.

Laraña Rodríguez-Cabello, Enrique (1993). "Modelos de interpretación y cuestiones de método en el estudio de las migraciones españolas». Política y Sociedad, $12,121-137$.

López GAY, Antonio (2007). Canvis residencials i moviments migratoris en la renovació poblacional de Barcelona. Tesis doctoral. Universitat Autònoma de Barcelona.

Martí, Mónica y Ródenas, Carmen (2004). «Migrantes y migraciones: de nuevo la divergencia en las fuentes estadísticas». Estadística Española, 46 (156), 293-321.

Maza Fernández, Adolfo y Villaverde Castro, José (2004). «Determinantes de la migración interregional en España: nuevas técnicas de análisis». Investigaciones Regionales, 4, 133-142.

Módenes Cabrerizo, Juan Antonio y Recaño Valverde, Joaquín (2003). El territori i la mobilitat migratòria dels joves a Catalunya. Barcelona: Secretaria General de Joventut. Generalitat de Catalunya.

Pérez Yruela, Manuel y Rinken, Sebastián (2005). La integración de los inmigrantes en la sociedad andaluza. Madrid: Consejo Superior de Investigaciones Científicas.

Pujadas, Isabel (2009). "Movilidad residencial y expansión urbana en la Región Metropolitana de Barcelona, 1982-2005». Scripta Nova: Revista Electrónica de Geografia y Ciencias Sociales. Barcelona: Universidad de Barcelona, 15 de mayo de 2009, XIII (290).

Pumares, Pablo; García Coll, Arlinda y Asensio, Ángeles (2006). La movilidad laboral y geográfica de la población extranjera en España. Madrid: Ministerio de Trabajo y Asuntos Sociales.

Puyol, Rafael (ed.) (1997). Dinámica de la población en España: Cambios demográficos en el último cuarto del siglo XX. Madrid: Síntesis.

Recaño Valverde, Joaquín (2002). «Movilidad geográfica de la población extranjera en España: Un fenómeno emergente». Cuadernos de Geografía, 72, 135-156. Universidad de Valencia. 
Recaño Valverde, Joaquín (2004). «Las migraciones internas de retorno en España durante la primera mitad de la década de los noventa: Implicaciones demográficas y territoriales». Geo Crítica / Scripta Nova. Revista Electrónica de Geografia y Ciencias Sociales, VIII (157).

- (2006). «Los intercambios poblacionales entre las regiones españolas». En: Fernández Cordón, J.A.; Leal Maldonado, J. (coords.). Análisis territorial de la demografía española. Madrid: Fundación Fernando Abril Martorell.

Recaño Valverde, Joaquín y Roig Vila, Marta (2003). "Internal Migration and Inequalities: The Influence of Migrant Origin on Educational Attainment in Spain». European Sociological Review, 19 (3), 299-317.

Recaño, Joaquín; Domingo, Andreu (2006). «Evolución de la distribución territorial y la movilidad geográfica de la población extranjera en España». En: AJA, E. y Arango, Joaquín (eds.). Veinte años de inmigración en España: Perspectivas jurídica y sociológica (1985-2004). Barcelona: Fundación CIDOB.

Reher, David y Requena, Miguel (2009). "The National Immigrant Survey of Spain: A new data source for migration studies in Europe». Demographic Research, 20 (12), 253-278.

Ródenas, Carmen y Martí, Mónica (1997). "¿Son bajos los flujos migratorios en España?». Revista de Economía Aplicada, V (15), 155-171.

- (2005). «El nuevo mapa de las migraciones interiores en España: Los cambios en el patrón de los sesenta». Investigaciones Regionales, 6, 21-39.

- (2006). «Reinterpretando el crecimiento de la movilidad de España: La población extranjera y las migraciones repetidas». Cuadernos Aragoneses de Economía, 2a época, 16 (1), 37-59.

- (2009a). "¿Son fiables los datos de migraciones del censo de 2001?». Revista de Economia Aplicada, XVII (50), 97-118.

- (2009b). "L'estimation des "fausses migrations" en Espagne». Population, 64-2.

Ros Jimeno, José (1968). «Las migraciones interiores y el I Plan de Desarrollo en España». Revista Internacional de Sociología, 103-104, 91-108.

SANTIllana del Barrio, Ignacio (1982). "Factores explicativos de los movimientos migratorios interprovinciales en España». Estudios Territoriales, 7, 25-70.

Silvestre RodríGueZ, Javier (2001). «Viajes de corta distancia: una visión espacial de las migraciones interiores en España 1877-1930». Revista de Historia Económica, 19 (2), 247-283.

- (2002). "Las migraciones interiores en España durante los siglos xix y xx: Una revisión bibliográfica». Ager. Revista de Estudios sobre Despoblación y Desarrollo Rural, 2, 227-248.

Solana Solana, Miguel (2005). «¿La constitución de una nueva ruralidad? Migración y cambio sociodemográfico en áreas rurales de Gerona: El caso del Empordanet». Documentos de Trabajo, 2. Centro de Estudios sobre la Despoblación y el Desarrollo de Áreas Rurales.

Tirado, Daniel A.; Pons, Jordi; Paluzie, Elisenda y Silvestre, Javier (2006). «Migraciones y aglomeraciones industriales en España a lo largo del siglo xx: Un estudio desde la Nueva Geografía Económica». Documentos de Trabajo FUNCAS, 318.

Torres Elizburu, Roberto (2007). «Las migraciones internas en el País Vasco durante el periodo 1991-2001: evidencias de un proceso de contraurbanización». Boletín de la A.G.E, 43, 85-105.

Zamora López, Francisco y Serrano Secanella, Pedro (2000). «Migraciones y cambios de vivienda». En: Taltavull, Paloma (coord.). Vivienda y familia. Madrid: Fundación Argentaria, Visor. 